\title{
A volumetric yield surface for compacted soils based on constant water content testing
}

\author{
C. Jayasundara ${ }^{1, *}, J$. Kodikara $^{2}$, and $A . N$. Zhou $^{3}$ \\ ${ }^{1} \mathrm{PhD}$ candidate, Department of Civil Engineering, Monash University, Melbourne, Australia \\ ${ }^{2}$ Professor, Department of Civil Engineering, Monash University, Melbourne, Australia \\ ${ }^{3}$ Senior Lecturer, Department of Civil Engineering, RMIT University, Melbourne, Australia
}

\begin{abstract}
Unsaturated soils exhibit various complex behaviours compared to saturated soils, such as collapse upon wetting. Therefore, understanding the response of unsaturated soils under general field conditions is essential for the design and construction of safe and economical geotechnical engineering structures. This research is based on the Monash-Peradeniya-Kodikara (MPK) framework proposed by Kodikara [1] for unsaturated compacted soils, which provides a direct link to the traditional compaction loaded curves and constant water content loading experiments. Kodikara [1] named the loaded compaction surface the loading wetting state boundary surface (LWSBS) and validated the model for a combination of loading and wetting stress paths. However, the experimental validation of the yield surface after drying stress paths was not addressed in the original paper. This paper reports the results of drying stress path tests carried out within the specific volume $(v)$,specific moisture ratio $\left(v_{w}\right)$ and mean net stress $(p)$ space of the MPK model, and observations suggest that the yield surface is unique after drying stress paths. Mathematical equations for the volumetric behaviour of unsaturated soils are derived using the constant degree of saturation hyperlines derived from constant water content testing, as this enables direct coupling with the soil water retention curve. Finally, the volumetric equations are validated based on the available experimental data.
\end{abstract}

\section{Introduction}

A typical soil consists of a skeleton of solid particles enclosing continuous voids that contain water and/or air. The unsaturated soil state may exhibit complicated behaviours, including swelling and collapse in comparison to the soil in the saturated soil state. These behaviours may affect the infrastructure performance of unsaturated soil with possible damage due to settlement or heave. In addition, during prolonged rainfall events, the degree of saturation may increase significantly, which may result in loss of shear strength leading to excessive deformation. Therefore, an improved understanding of the behaviour of unsaturated compacted soils based on phenomenological observations of unsaturated soil is essential. Various types of constitutive models have been developed over the last several decades to determine the general behaviour of unsaturated soils [2-5], but a generalised model which captures observed phenomenological features and is at the same time relatively simple to apply to field problems would be valuable. The aim of this paper is, therefore, to highlight the initial development of a generalised constitutive model for unsaturated compacted soils by coupling hydraulic and mechanical behaviour. This paper outlines some developments in the constitutive model, in particular, the volumetric yield surface and its uniqueness when measured with constant water content loading.

\subsection{Monash-Peradeniya-Kodikara (MPK) model}

Kodikara [1] proposed a framework called the MPK Monash - Peradeniya -Kodikara (MPK) model to give prominence to the water content in place of suction following the work input equation proposed by Houlsby [6]. The primary advantage of this approach is that the MPK framework revealed for the first time the direct relevance of the traditional compaction curves to constitutive soil modelling. In addition, much simpler and faster constant water content loading can be used to produce the experimental data required as input. The validation of the framework was carried out using compacted kaolin and natural Merri Creek soil for 1-D stress states $[\underline{7}, \underline{8}]$. Subsequently, the MPK framework was extended to the triaxial stress state by Abeyrathne [9] and was validated for isotropic and triaxial stress states based on the development of a constitutive model. However, it can only be considered a partial model, which utilises water content instead of suction in accordance with the work equation proposed by Houlsby [6]. Nonetheless, it is a practical model which enables field questions to be answered with a specific volume $(v)$ and specific moisture ratio $\left(v_{\mathrm{w}}\right)$ or degree of saturation $\left(S_{\mathrm{r}}\right)$. The MPK model has two surfaces, namely the loading wetting state boundary surface (LWSBS) and tensile

\footnotetext{
* Corresponding author: Chathurika.jayasundara@monash.edu
} 
failure surface with two primary lines: the air transition line (ATL) and the saturation line (the $v=v_{\mathrm{w}}$ line or NCL). The LWSBS can be considered to comprise a family of compaction curves for various loadings, and it is considered to represent the loosest states of compacted soil, in the same way that the NCL represents the loosest states for saturated soil. To establish the uniqueness and concept validation of the LWSBS upon wetting, loading/unloading combinations in an extensive number of experiments were carried out in the 1-D stress state by Islam and Kodikara [7], Kodikara, Islam [8] and in the isotropic stress state by Abeyrathne [9] for less reactive compacted kaolin and highly reactive Merri Creek soil. However, this research considered only paths containing loading/unloading and wetting stress paths, and its applicability to paths containing drying was not examined. This paper examines the general validity of the LWSBS and develops mathematical equations for it based on constant water content testing.

\section{Experimental validation}

Trial isotropic testing was initially carried out in an unsaturated soil triaxial apparatus under the constant suction condition for different moisture contents at a rate of $2 \mathrm{kPa} / \mathrm{hr}$ for loading and $1 \mathrm{kPa} / \mathrm{hr}$ for wetting and drying stress paths with subsequent equilibrium time of 24 hours is selected for future testing. In total, six experiments were carried out during the drying/loading series of tests. The first three stress paths (T1, T2 and T3) were designed considering constant suction loading-unloading-dryingconstant water content loading paths (ABCDE), as shown in Fig. 1 for Test 1 (T1). The other three independent constant water content tests (T4, T5 and T6) were carried out for the water contents arrived at by the drying stress path tests. The path (T4) corresponding to test T1 is shown in Fig. 1.

\subsection{Sample preparation}

Kaolin, with the commercial name Eckalite 1, was selected as a suitable soil for the experiments as it has been widely used for unsaturated soil modelling, including research related to the MPK framework at Monash University. The dry kaolin ( $L L=60.5 \%$, $P L=27.9 \%$ ) was hand-mixed with distilled water at a water content of $25 \%$ for the drying loading tests, and for the other tests, sample preparation was carried out considering the final water content of the samples after drying. The samples were then placed in sealed plastic bags for $24 \mathrm{hrs}$ for equalisation. The moisture content was checked by taking three small samples and measuring the water contents. Th soil was then statically compacted to $50 \mathrm{kP}$ in five similar layers to achieve the loosest state of compacted soils corresponding to that moisture content. The static compaction procedure utilised in this research is identical to that employed by Abeyrathne [9].

\subsection{Stress paths}

The first three tests were carried out under three suction ranges: $100 \mathrm{kPa}-200 \mathrm{kPa}(\mathrm{T} 1), 200 \mathrm{kPa}-300 \mathrm{kPa}(\mathrm{T} 2)$ and $300 \mathrm{kPa}-400 \mathrm{kPa}(\mathrm{T} 3)$. The test $\mathrm{T} 1$ was designed for the lowest suction that can be achieved using the experimental set-up. Table1 and Fig. 1 show the stress paths followed in test $\mathrm{T} 1$. The sample was first equalised $\left(\mathrm{AA}^{\prime}\right)$ at the mean net stress of $10 \mathrm{kPa}$ and suction of $100 \mathrm{kPa}$. The duration of the equalisation was 14 days. Constant suction loading and unloading cycle ( $\left.\mathrm{A}^{\prime} \mathrm{BB}^{\prime} \mathrm{C}\right)$ was then performed on the soil sample over a net stress change to $50 \mathrm{kPa}$, and then the sample was dried to $200 \mathrm{kPa}$ suction under the net stress of $10 \mathrm{kPa}$. Finally, constant water content loading was performed on the sample to mean net stress of $250 \mathrm{kPa}$. The B', C', D', and E' states are not marked in Fig. 1 as there was no significant change during the $24 \mathrm{hr}$ equalisation.

Table 1. T1 stress paths

\begin{tabular}{|c|c|c|c|c|}
\hline \multicolumn{3}{|c|}{ Stage } & \multirow{2}{*}{$\begin{array}{l}\text { Net stress } \\
\qquad(\mathrm{kPa})\end{array}$} & \multirow{2}{*}{$\begin{array}{l}\text { Suction } \\
(\mathrm{kPa})\end{array}$} \\
\hline From & To & Description & & \\
\hline A & $A^{\prime}$ & $\begin{array}{l}\text { Initial } \\
\text { equalisation }\end{array}$ & 10 & 100 \\
\hline$A^{\prime}$ & B & $\begin{array}{l}\text { Isotropic } \\
\text { loading }\end{array}$ & $10 \rightarrow 50$ & 100 \\
\hline B & $\mathrm{B}^{\prime}$ & Equalization & 50 & 100 \\
\hline $\mathrm{B}^{\prime}$ & $\mathrm{C}$ & $\begin{array}{l}\text { Isotropic } \\
\text { unloading }\end{array}$ & $50 \rightarrow 10$ & 100 \\
\hline $\mathrm{C}$ & $\mathrm{C}^{\prime}$ & Equalization & 10 & 100 \\
\hline $\mathrm{C}^{\prime}$ & $\mathrm{D}$ & Drying & 10 & $100 \rightarrow 200$ \\
\hline $\mathrm{D}$ & $D^{\prime}$ & Equalization & 10 & 200 \\
\hline$D^{\prime}$ & $\mathrm{E}$ & $\begin{array}{l}\text { Constant } \\
\text { water content } \\
\text { loading }\end{array}$ & $10 \rightarrow 250$ & $200 \rightarrow 190$ \\
\hline $\mathrm{E}$ & $E^{\prime}$ & Equalization & 250 & 190 \\
\hline
\end{tabular}

During initial equalisation, collapse behaviour is observed where the soil yields during the initial equalisation wetting due to ID lower initial stress compaction of the sample. The subsequent loading path A'B also depicts some yielding behaviour, suggesting that the reduction of the specific volume of ID compaction is lower than that of isotropic compaction. The yielding stress of Fig. 1(b) is nearly $15 \mathrm{kPa}$. Then during the unloading stress path $\mathrm{B}^{\prime} \mathrm{C}$ the soil behaves elastically. Fig. 1(c) shows the behaviour of the sample during the drying stress path on the $v-p$ plane. One of the highlighted phenomenological observations during test $\mathrm{T} 1$ is that the increase in yield stress after the drying where the drying results in yielding of soil can be observed during stress path DE in Fig. 1(b). Similarly, T2 and T3 were carried out for higher suction ranges of $200 \mathrm{kPa}$ to $300 \mathrm{kPa}$ and $300 \mathrm{kPa}$ to $400 \mathrm{kPa}$, respectively.

\footnotetext{
* Corresponding author: Chathurika.jayasundara@monash.edu
} 


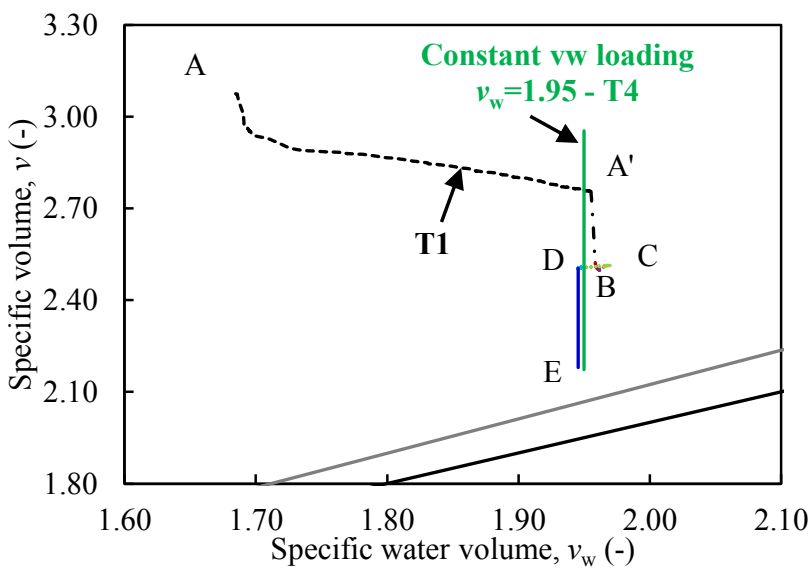

(a) $v-v_{\text {w }}$ plane

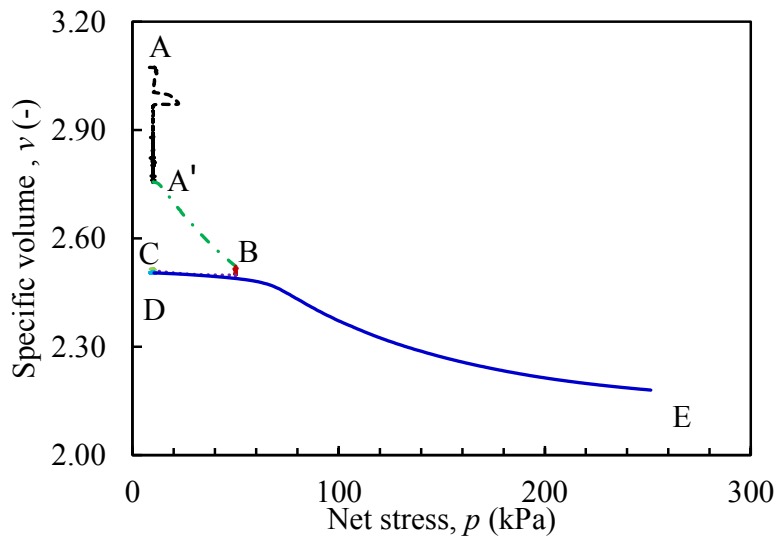

(b) $v$ - $p$ plane

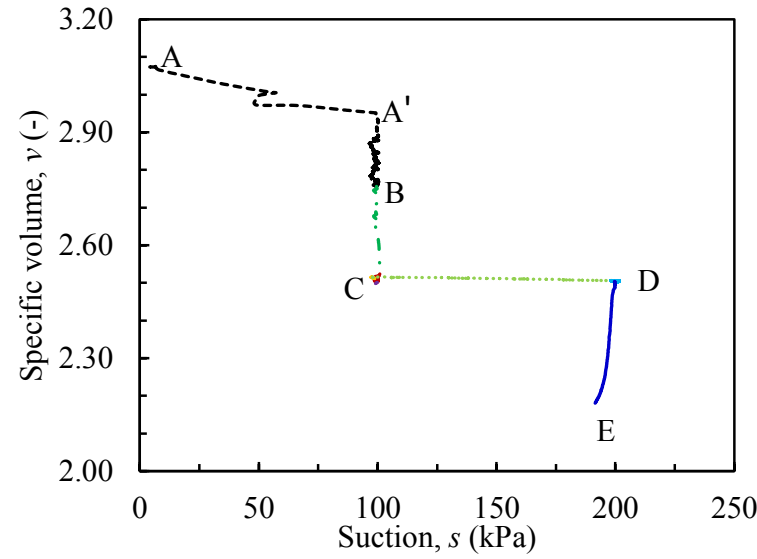

(c) $v-s$ plane

Fig. 1. Experimental results for T1 (and T4 only in (a))

\subsection{Results}

As the primary objective of the testing was to clarify the uniqueness of the LWSBS during drying, the constant water content loading stress paths were compared with the drying loading stress paths. Fig. 2 summarises the comparison of the six tests (T1, T2, T3, T4, T5 and T6), and gives the corresponding variation of the specific volume with the loading with or without drying where

\footnotetext{
Corresponding author: Chathurika.jayasundara@monash.edu
}

both stress paths tend to follow similar stress paths after yielding. Fig. 2 (a), (b) and (c) give a comparison of these loading paths for the respective specific water contents of $1.82,1.85$ and 1.93 , respectively.

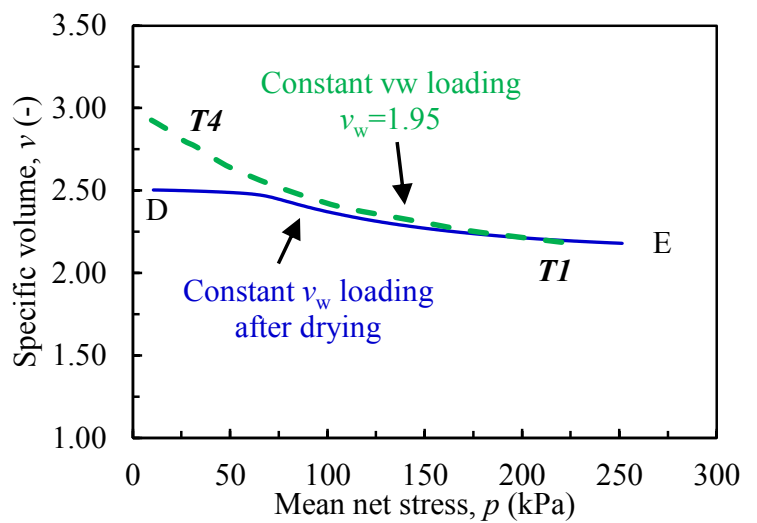

(a)

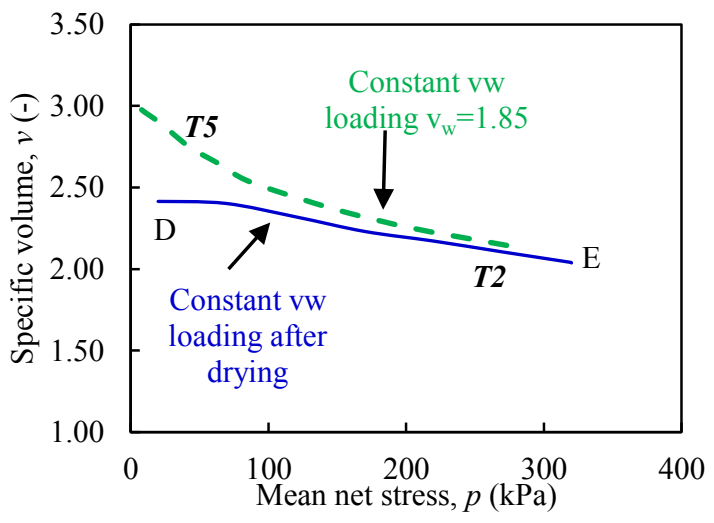

(b)

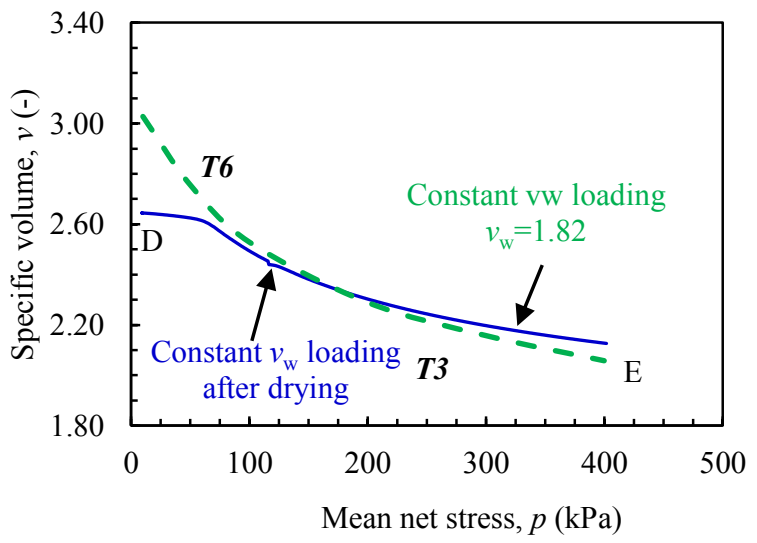

(c)

Fig. 2. Validation of loading paths with and without drying

On the basis of the observations in Fig. 2 of loading with drying and without drying, the experimental results followed a similar trend for the change in specific volume. For example, as Fig. 2(a) shows, after yielding at $60 \mathrm{kPa}$, stress path DE follows the T4 constant water content loading $\left(v_{\mathrm{w}}=1.95\right)$ stress path. It is apparent that the yielding stress of $60 \mathrm{kPa}$ is higher than the initial yield stress of $50 \mathrm{kPa}$, which occurred due to the drying of the 
sample. Similarly, the results of T2 and T5, given in Fig. 2(b) for $v_{\mathrm{w}}=1.85$ and the results of T3 and T6, presented in Fig. 2(c) for $v_{\mathrm{w}}=1.82$ followed analogous behaviour upon loading. In addition, the yielding stresses achieved after drying to the suctions of $300 \mathrm{kPa}$ in $\mathrm{T} 2$ and $400 \mathrm{kPa}$ in $\mathrm{T} 3$ were $70 \mathrm{kPa}$ and $80 \mathrm{kPa}$ respectively. It should be noted that the yield stress of the samples was $50 \mathrm{kPa}$ before drying. Therefore, particularly after yielding, the soil starts to follow the same stress paths. In other words, there are similar patterns in the drying loading stress paths (DE in T1, T2, T3) and loading stress paths (T4, T5, T6). Hence, it can be concluded that the LWSBS can be verified as unique for loading/unloading, wetting and drying stress states.

In summary, the experimental results show: (1) the yielding stress due to loading after drying increases in comparison to that prior to drying; (2) the stress path of loading follows the same path after yielding without drying. This highlights that the LWSBS developed through constant water content loading with wetting is applicable to subsequent paths containing drying. In other words, the uniqueness of the LWSBS as a volumetric yield surface is confirmed.

\section{Development of concepts for a generalised MPK model}

Houlsby [6], formulated the work equation for unsaturated soils considering the volumetric behaviour using the principles of energy given in Eq. 1 and Eq. 2. According to Eq. 1, when the constant $S_{\mathrm{r}}$ loading is carried out, the behaviour of Bishop's effective stress ( $\left.p^{*}=p_{\text {net }}+S_{\mathrm{r}} s\right)$ depends only on the volumetric strain ( $\left.\varepsilon_{\mathrm{v}}\right)$. On the other hand, according to Eq. 2, when constant $e_{\mathrm{w}}$ loading is carried out, the behaviour of the net stress ( $\left.p_{\text {net }}\right)$ depends only on the volumetric strain $\left(\varepsilon_{v}\right)$. The latter principal was utilised by Kodikara [1] in the formulation of the MPK framework.

$$
\begin{array}{r}
\mathrm{d} W=\left(p_{\text {net }}+S_{r} s\right) \mathrm{d} \varepsilon_{\mathrm{v}}-s^{*} \mathrm{~d} S_{\mathrm{r}} \\
\mathrm{d} W=p_{\text {net }} \mathrm{d} \varepsilon_{\mathrm{v}}+\frac{s}{1+e} \mathrm{~d} e_{\mathrm{w}}
\end{array}
$$

where $n$ is porosity, $s$ is suction and $s^{*}$ is modified suction. The generalised MPK model is proposed on the basis of Eq. 1, where the constant $S_{\mathrm{r}}$ loading hyperlines are considered. The key reasons for selecting constant $S_{\mathrm{r}}$ loading hyperlines are: (1) they provide direct coupling capabilities with the SWRC; (2) the yield surface and shear strength surface can be easily found; (3) Bishop's effective stress can be defined well, and the final mathematical formulation could follow the work Eq. 1. In this paper, only the derivation and validations of the mathematical equations for the volumetric behaviour are discussed.

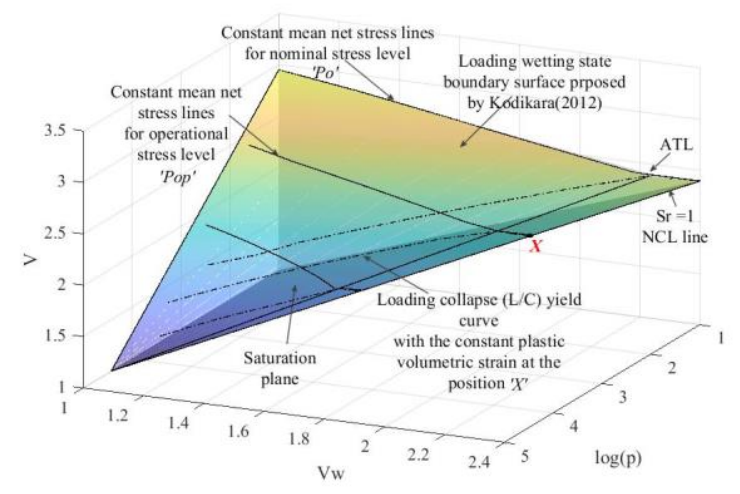

Fig. 3. The volumetric surface of a generalised MPK model

The LWSBS proposed by Kodikara [1] is considered as the upper boundary of the model while the saturation plane is regarded as the lower boundary of the model, as shown in Fig. 3. The LWSBS consists of two major divisions, demarcated by the air transition line (ATL). The section which has a degree of saturation less than the ATL is named the dry side, whereas the other is designated as the wet side. According to the work equation proposed by Houlsby [6], the work conjugates of the proposed model are determined as $p^{*} \mathrm{~d} \varepsilon_{\mathrm{v}}, s^{*} \mathrm{~d} S_{\mathrm{r}}$ (Bishop's effective stress state approach) for the wet side and $p \mathrm{~d} \varepsilon_{\mathrm{v}}, \mathrm{d} e_{\mathrm{w}}$ (independent stress state approach) for the dry side separately. Finally, it is expected to transform the stresses to $p^{*}$ and $s^{*}$ according to the transformation matrix concept proposed by Buscarnera and Di Prisco [10].

\section{Theoretical development of the proposed model}

\subsection{Volumetric behaviour}

Abeyrathne [9] proposed the yield equation for constant specific water volume hyperlines for the volumetric yield surface, as given in Eq. 3, which is based on Eq. 2, where the second work conjugate $\left(\frac{s}{1+e} \mathrm{~d} e_{\mathrm{w}}\right)$ becomes zero during the loading.

$$
v=v_{0}-\lambda_{\mathrm{w}} \ln \left(p / p_{\mathrm{o}}\right)
$$

where $v_{0}$ is the reference specific volume at reference st ress $\left(p_{\mathrm{o}}\right)$ and $\lambda_{\mathrm{w}}$ is the stiffness parameter for changes $i$ $\mathrm{n}$ mean net stress at constant $\left(v_{\mathrm{w}}\right) \cdot v_{0}$ and $\lambda_{\mathrm{w}}$ are assume $\mathrm{d}$ to be linear functions of $v_{w}$ as given in Eqs.(4) and (5):

$$
\lambda_{\mathrm{w}}=C_{1}-k_{1}\left(v_{\mathrm{w}}-v_{\mathrm{w}}^{\mathrm{L}}\right)
$$

\footnotetext{
* Corresponding author: Chathurika.jayasundara@monash.edu
} 


$$
v_{0}=C_{2}-k_{2}\left(v_{\mathrm{w}}-v_{\mathrm{w}}^{\mathrm{L}}\right)
$$

In Eqs (4) and (5)., $v_{\mathrm{w}}^{\mathrm{L}}$ is the specific volume at the air transition line (ATL) at reference stress $\left(p_{\mathrm{o}}\right)$ and $C_{1}, k_{1}, C_{2}$ and $k_{2}$ (see Table 2) are assumed to be constants for a particular soil which can be found by fitting experimental data.

However, as explained above, the degree of saturation is the most reliable dependent variable, which affects the stiffness parameter $[\underline{4}, \underline{11}, \underline{12}]$. Therefore, the degree of saturation is used for the generalised constitutive model instead of the specific water volume ( $\left.v_{\mathrm{w}}\right)$ and Eq. (3) is transformed to the degree of saturation $\left(S_{\mathrm{r}}\right)$, as given in

$$
v=v_{0}-\lambda_{\mathrm{S}_{\mathrm{r}}} \ln \left(p / p_{\mathrm{o}}\right)
$$

where, $v_{0}$ is the reference specific volume at reference stress $\left(p_{\mathrm{o}}\right)$ and $\lambda_{\mathrm{S}_{\mathrm{r}}}$ is the stiffness parameter for changes in mean net stress at a constant degree of saturation $\left(S_{\mathrm{r}}\right)$. $v_{0}$ and $\lambda_{\mathrm{S}}$ are assumed to be linear functions of $S_{\mathrm{r}}$ as given in Eqs. (7) and (8).

$$
\begin{aligned}
& \lambda_{\mathrm{S}_{\mathrm{r}}}=C_{1}-k_{1}\left(\left(v_{0}-1\right) S_{r}-\left(v_{\mathrm{o}}^{\mathrm{L}}-1\right) S_{\mathrm{r}}^{\mathrm{L}}\right) \\
& v_{0}=C_{2}-k_{2}\left(\left(v_{0}-1\right) S_{r}-\left(v_{\mathrm{o}}^{\mathrm{L}}-1\right) S_{\mathrm{r}}^{\mathrm{L}}\right)
\end{aligned}
$$

where $S_{\mathrm{r}}$ is the degree of saturation at reference stress and $v_{\mathrm{o}}^{\mathrm{L}}$ and $S_{\mathrm{r}}^{\mathrm{L}}$ are the specific volume and degree of saturation at the reference stress on the volumetric yield surface at the ATL.

Eq. 9 indicates the general form of the specific volume change of the volumetric yield surface, which is represented by a series of normal compression lines in the $v, v_{\mathrm{w}}, p$ space.

$$
\mathrm{d} v=-\lambda_{\mathrm{S}_{\mathrm{r}}} \frac{\mathrm{d} p}{p}-\frac{\partial \lambda_{\mathrm{S}_{\mathrm{r}}}}{\partial S_{\mathrm{r}}} \ln \left(p / p_{\mathrm{o}}\right) d S_{\mathrm{r}}
$$

These parameters can be found by simple water content testing, and a detailed description of the evaluation of these parameters is given in Abeyrathne [9]. In addition, the yield compression hyperlines are only valid for the dry side of the ATL. When $S_{\mathrm{r}}^{\mathrm{L}}<S_{\mathrm{r}}$ the effective stress concept is acceptable, and therefore the saturated compression index $\lambda_{\text {sat }}$ is assumed.

Similar to yielding hyperlines, the elastic behaviour of the generalized MPK model is defined by Eq. 10, where $k_{\mathrm{S}_{\mathrm{r}}}$ and $\frac{\partial k_{\mathrm{S}_{\mathrm{r}}}}{\partial S_{\mathrm{r}}}$ are given by Eq. 11 and Eq. 12, respectively.

$$
\begin{array}{r}
\mathrm{d} v^{\mathrm{e}}=-k_{\mathrm{S}_{\mathrm{r}}} \frac{\mathrm{d} p}{p}-\frac{\partial k_{\mathrm{S}_{\mathrm{r}}}}{\partial S_{\mathrm{r}}} \ln \left(p / p_{\mathrm{o}}\right) d S_{\mathrm{r}} \\
k_{\mathrm{S}_{\mathrm{r}}}=-\frac{-k_{\mathrm{w}}}{1-\alpha_{\mathrm{ES}} S_{\mathrm{r}}}
\end{array}
$$

\footnotetext{
Corresponding author: Chathurika.jayasundara@monash.edu
}

$$
\frac{\partial k_{\mathrm{S}_{\mathrm{r}}}}{\partial S_{\mathrm{r}}}=-\frac{k_{\mathrm{w}} \alpha_{\mathrm{ES}}}{\left(1-\alpha_{\mathrm{ES}} S_{\mathrm{r}}\right)^{2}}
$$

where, $\boldsymbol{\alpha}_{\mathrm{ES}}$ is the shrink/swell gradient and $k_{\mathrm{w}}$ is the unloading/reloading gradient during constant water content testing. Similar to the yield hyperlines, the unloading/reloading gradient is only valid for the dry side of the ATL. When $S_{\mathrm{r}}^{\mathrm{L}}<S_{\mathrm{r}}$ the effective stress concept is acceptable, and therefore the saturated compression index $k_{\text {sat }}$ is assumed.

Table 2. Model parameters

\begin{tabular}{|c|c|}
\hline Parameter & Model value \\
\hline$C_{1}$ & 0.175 \\
\hline$k_{1}$ & 0.01 \\
\hline$C_{2}$ & 2.38 \\
\hline$k_{2}$ & 0.48 \\
\hline$k_{\mathrm{w}}$ & 0.01 \\
\hline$v_{\text {sat }}^{0}$ & 2.4 \\
\hline$k_{\text {sat }}$ & 0.021 \\
\hline$\lambda_{\text {sat }}$ & 0.1754 \\
\hline$p_{\mathrm{o}}$ & 10 \\
\hline$S_{\mathrm{r}}^{\mathrm{L}}$ & 0.89 \\
\hline$\alpha_{\mathrm{ES}}$ & 0.6 \\
\hline
\end{tabular}

\subsection{Experimental validation of volumetric behaviour}
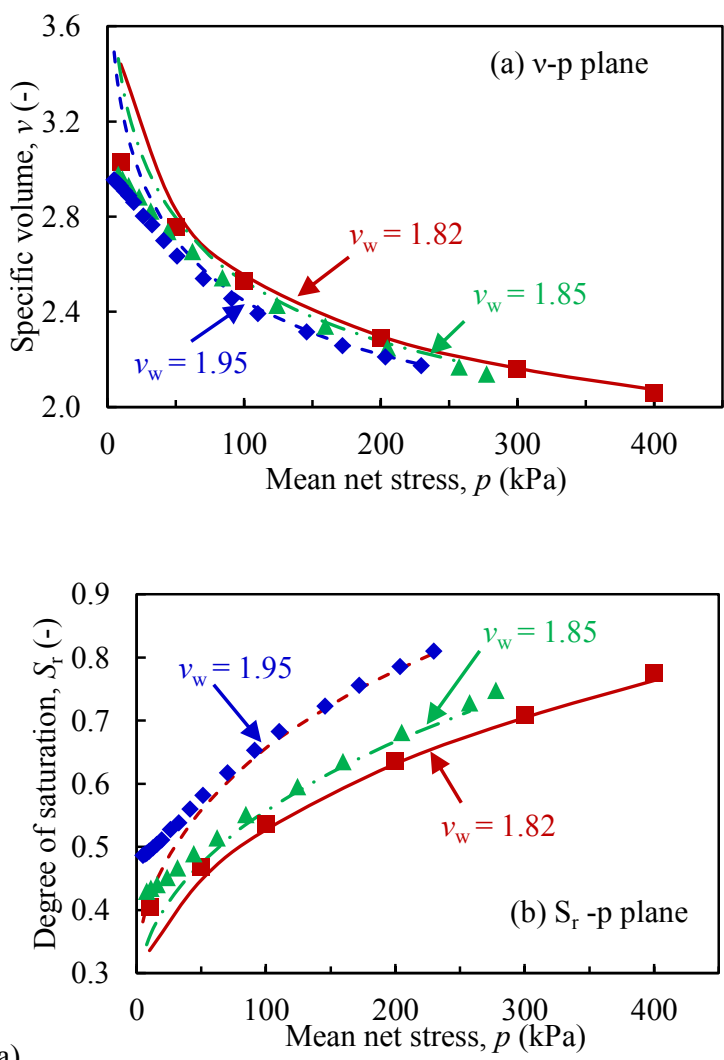

Fig. 4. Comparison of simulated and experimental results 
The constant water content tests T4, T5 and T6, were analytically validated with the proposed equation, and a comparison of the results is provided in Fig. 4 (a) and (b) in the $v-p$ plane and $S_{\mathrm{r}}-p$ plane respectively. The required model parameters for Space White kaolin were identified based on a series of constant water content tests by Abeyrathne [9], and the results are given in Table 2 .

As the figures show, the theoretical equations capture the volumetric response of specific volume and the change of $S_{\mathrm{r}}$ well. For example, the $v_{\mathrm{w}}$ of the 1.82 hyperline is placed above the $v_{\mathrm{w}}$ of the 1.95 hyperline and the behaviour is well captured by the volumetric equation. Hence, the phenomenological observation of the increase of the compressibility gradient with the decrease of moisture content is evident in Fig. 4.

\section{Discussion and conclusion}

The primary aim of this paper was to validate the uniqueness of the yield surface through drying loading stress paths, as the previous research on the MPK framework was based on loading/unloading and wetting stress paths. Based on the results of the experiments carried out: (1) an increase in yield stress during loading after drying in comparison to the loading prior to drying was observed; (2) during yielding, a similar pattern of stress path was found with or without drying. This highlights the uniqueness of the LWSBS, which developed through constant water content tests are applicable to loading/unloading and wetting/drying stress paths. The second aim of this paper was to identify the possibility of a generalised model, which follows the Houlsby [6] work in Eq.1 and the formulation of mathematical equations for yielding and elastic behaviour considering the degree of saturation. As the paper has shown, the proposed volumetric equations of the volumetric yield surface capture the volumetric response of the proposed model well, and the experimental evidence follows similar stress paths. In the future, it is expected to extend the model to capture hydromechanical coupled behaviour and triaxial behaviour.

\section{References}

1. J. Kodikara, New framework for volumetric constitutive behaviour of compacted unsaturated soils. Canadian Geotechnical Journal, 2012. 49(11): p. 1227-1243.

2. E.E. Alonso, A. Gens, and A. Josa, $A$ constitutive model for partially saturated soils. Géotechnique, 1990. 40(3): p. pp.405-430.

3. S. Wheeler, R. Sharma, and M. Buisson, Coupling of hydraulic hysteresis and stressstrain behaviour in unsaturated soils. Géotechnique, 2003. 53(1): p. 41-54.

4. $\quad$ A.-N. Zhou, et al., Interpretation of unsaturated soil behaviour in the stress-Saturation space, I: Volume change and water retention behaviour.
Computers and Geotechnics, 2012. 43: p. 178187.

5. D. Sheng, D.G. Fredlund, and A. Gens, A new modelling approach for unsaturated soils using independent stress variables. Canadian Geotechnical Journal, 2008. 45(4): p. 511-534.

6. G. Houlsby., The work input to an unsaturated granular material. Géotechnique, 1997. 47(1): p. 193-196.

7. T. Islam, and J. Kodikara, Interpretation of the loading-wetting behaviour of compacted soils within the "MPK" framework. Part I: Static compaction 1. Canadian Geotechnical Journal, 2015. 53(5): p. 783-805.

8. J. Kodikara, T. Islam, and P. Rajeev, Interpretation of the loading-wetting behaviour of compacted soils within the "MPK" framework. Part II: Dynamic compaction 1. Canadian Geotechnical Journal, 2015. 53(5): p. 806-827.

9. W.K.A.P. Abeyrathne, A new modelling approach for compacted clayey soils using specific water volume as a state variable, in Civil Engineering. 2017, Monash University: Melbourne.

10. G. Buscarnera, and C. Di Prisco, Discussing the definition of the second-order work for unsaturated soils. International journal for numerical and analytical methods in geomechanics, 2012. 36(1): p. 36-49.

11. A.-N Zhou, et al., Interpretation of unsaturated soil behaviour in the stress-saturation space: II: constitutive relationships and validations. Computers and Geotechnics, 2012. 43: p. 111123.

12. A. Zhou, et al., Including degree of capillary saturation into constitutive modelling of unsaturated soils. Computers and Geotechnics, 2018. 95: p. 82-98.

* Corresponding author: Chathurika.jayasundara@monash.edu 